\title{
Resistência antimicrobiana e ocorrência de micro-organismos patogênicos e indicadores em frangos orgânicos e convencionais: estudo comparativo
}

\author{
Luciane Silvia Rossa ${ }^{1}$ \\ Evelyn Von Rosen Stahlke ${ }^{1}$ \\ Deisy Cristina Diez ${ }^{1}$ \\ Saulo Henrique Weber ${ }^{1}$ \\ Sônia Cachoeira Stertz ${ }^{2}$ \\ Renata Ernlund Freitas de Macedo ${ }^{1 *}$ \\ ${ }^{1}$ Escola de Ciências Agrárias e Medicina Veterinária, Pontifícia Universidade Católica do Paraná \\ BR 376, km 14, CEP 83010-500, São José dos Pinhais - PR, Brasil \\ ${ }^{2}$ Departamento de Engenharia Química, Universidade Federal do Paraná \\ Rua Cel. Francisco H. dos Santos, 210, CEP 81531-970, Curitiba - PR, Brasil \\ * Autor para correspondência \\ renata.macedo@pucpr.br
}

Submetido em 22/04/2013

Aceito para publicação em 04/07/2013

\section{Resumo}

O objetivo deste trabalho foi avaliar comparativamente a ocorrência de bactérias patogênicas e indicadoras e a resistência antimicrobiana de enterobactérias isoladas de carcaças de frango orgânico e de frango convencional. Foram avaliadas 50 carcaças de frango congeladas, 25 de criação orgânica e 25 convencionais de cinco marcas comerciais adquiridas no Sul e Sudeste do Brasil. Foram realizadas contagens de mesófilos, psicrotróficos, coliformes totais, Escherichia coli, Staphylococcus coagulase positiva e pesquisa de Salmonella sp. A resistência antimicrobiana foi avaliada pelo método de disco-difusão. Os resultados foram analisados por Anova e teste de Tukey para detectar diferenças entre as marcas dentro de cada grupo (orgânico e convencional) e pelo teste de Kolmogorov-Smirnov para detectar diferença entre os grupos orgânico x convencional. As diferenças entre a resistência antimicrobiana nos grupos foram calculadas pelo teste do Qui-quadrado $(P<0,05)$. As carcaças orgânicas apresentaram maior contaminação microbiana em comparação às carcaças convencionais, contudo as enterobactérias isoladas do grupo orgânico mostraram menor resistência antimicrobiana. Tetraciclina foi o antibiótico com a maior frequência de resistência em ambos os sistemas de criação. O uso restrito ou ausente de antibióticos na produção orgânica pode contribuir para o menor risco de transmissão de bactérias antibióticoresistentes pelo consumo de carne de frango.

Palavras-chave: Contaminação microbiológica; Frango orgânico; Resistência a antibióticos

\section{Abstract}

Antimicrobial resistance and occurrence of indicator and pathogenic bacteria in organic and conventional chicken meat: comparative study. The aim of this study was to comparatively assess the 
occurrence of pathogenic and indicator bacteria, and the antimicrobial resistance of Enterobacteriaceae, isolated from organic and conventional chicken carcasses. Fifty frozen chickens were assessed from five different commercial brands purchased at retail stores in the South and Southeast regions of Brazil. Of these chickens, 25 were conventionally farmed and 25 were organically farmed. Mesophilic and psychrotrophic counts were made, as well as counts for total coliform, Escherichia coli, coagulase-positive Staphylococcus and the assessment of Salmonella sp. Antimicrobial resistance was evaluated using the disk diffusion method. The results were statistically analyzed by ANOVA, and Tukey's test was used to compare means between brands within the organic and conventional groups. The Kolmogorov-Smirnov test was used to compare bacterial counts between organic and conventional group. Differences of antimicrobial resistance between groups were calculated using the Chi square test $(\mathrm{P}<0.05)$. The organic chicken carcasses showed higher microbiological contamination $(\mathrm{P}<0.05)$ compared to conventional carcasses; however, Enterobacteriaceae from the organic chicken showed lower antimicrobial resistance. The highest frequency of resistance in Enterobacteriaceae isolated from both organic and conventional chicken was tetracycline. The restricted use or absence of antibiotics in organic farming practices can lower the risk of dissemination of antibiotic resistant bacteria when chicken is consumed.

Key words: Antimicrobial resistance; Microbiological contamination; Organic chicken

\section{Introdução}

Em virtude da ocorrência de enfermidades associadas ao consumo de alimentos contaminados por microorganismos patogênicos, tem-se verificado aumento da preocupação dos consumidores com a inocuidade dos produtos que consomem (REMBIAŁKOWSKA; ŚREDNICKA, 2009).

A contaminação microbiológica dos alimentos causa preocupação à saúde pública tanto pela ação patogênica dos micro-organismos quanto pela crescente resistência antimicrobiana verificada em cepas bacterianas que podem ocasionar comprometimento no tratamento de infecções em humanos. A resistência antimicrobiana de patógenos isolados de carnes está associada ao uso indiscriminado de antibióticos nos animais de produção, reforçando a necessidade do uso prudente de antibióticos por parte dos criadores (KILONZO-NTHENGE et al., 2008).

Como resultado da tendência de consumo de alimentos mais saudáveis e isentos de aditivos químicos, a demanda por alimentos orgânicos tem mostrado grande crescimento nas últimas décadas (HERMANSEN et al., 2004; FANATICO et al., 2005; TUYTTENS et al., 2008; GUÉGUEN; PASCAL, 2010). Na produção de carne orgânica é proibido o uso de antibióticos para promover crescimento dos animais (CRABONE et al., 2005; BRASIL, 2008) e a terapêutica é realizada com tratamentos alternativos à base de extratos de plantas (GRIGGS; JACOB, 2005).
Entre as carnes orgânicas, a carne de frango é uma das mais ofertadas no mercado nacional. Porém, pouco se conhece sobre a qualidade microbiológica da carne comercializada ao consumidor e de seu potencial em veicular micro-organismos antibiótico resistentes pelo seu consumo. Neste contexto, o objetivo do presente trabalho foi avaliar a ocorrência de bactérias indicadoras e patogências e verificar a resistência antimicrobiana de enterobactérias isoladas de carne de frangos orgânicos comercializados no Sul e Sudeste do País. A comparação dos mesmos parâmetros em carne de frango convencional comercializada sob as mesmas condições também foi realizada.

\section{Material e Métodos}

\section{Delineamento do estudo}

Foram avaliadas 50 carcaças de frangos, sendo 25 carcaças provenientes de sistema de produção orgânico e 25 de sistema de produção convencional. Para ambos os sistemas de produção foram adquiridas carcaças inteiras e congeladas de cinco diferentes fornecedores ou marcas comerciais, representadas por cinco unidades amostrais. As carcaças de frango orgânico foram adquiridas aleatoriamente em feiras orgânicas, mercados ou por venda direta do produtor e provenientes dos estados de Espírito Santo, Paraná, Santa Catarina e São Paulo. Todas as carcaças orgânicas avaliadas possuíam certificação de produto orgânico concedido por instituição reconhecida 
no País (IBD, Ecovida ou Ecocert). As carcaças de frango convencional foram adquiridas no comércio varejista de Curitiba/PR e eram provenientes do Distrito Federal, Mato Grosso, Paraná e Santa Catarina. Após a aquisição, as carcaças foram transportadas ao laboratório de análise em condições que as mantivessem congeladas e mantidas a temperatura $-18^{\circ} \mathrm{C}$ até o momento da análise.

\section{Análises microbiológicas}

O descongelamento das carcaças de frango foi realizado por imersão em água seguindo procedimento oficial padronizado (BRASIL, 1998). Para as determinações microbiológicas procedeu-se a coleta asséptica de $25 \mathrm{~g}$ da musculatura e da pele do peito das carcaças de frango, que foram homogeneizadas em $225 \mathrm{~mL}$ de água peptonada $0,1 \%$ esterilizada (HIMEDIA, RM001, Mumbai, Índia), com o auxílio do homogeneizador (Stomacher). Posteriormente, procedeu-se a diluição seriada de $1 \mathrm{~mL}$ das amostras em $9 \mathrm{~mL}$ de água peptonada estéril $0,1 \%$ seguida de semeadura em placas para as contagens microbiológicas, que foram realizadas em duplicata e de acordo com Brasil (2003) e Silva et al. (2010). A contagem total de aeróbios mesófilos foi realizada em ágar PCA (Plate Count Agar - HIMEDIA, M091, Mumbai, Índia) com incubação a $37^{\circ} \mathrm{C}$ por $48 \mathrm{~h}$. A contagem total de aeróbios psicrotróficos foi realizada em ágar PCA (Plate Count Agar - HIMEDIA, M091, Mumbai, Índia) com incubação a $17^{\circ} \mathrm{C}$ por $16 \mathrm{~h}$, seguida de nova incubação a $4^{\circ} \mathrm{C}$ por $72 \mathrm{~h}$. As contagens de coliformes totais e de Escherichia coli foram realizadas em placas Petrifilm EC (3M, St Paul, USA) com incubação a $37^{\circ} \mathrm{C}$ por $48 \mathrm{~h}$.

A contagem de Staphylococcus coagulase positiva foi realizada em ágar Baird-Parker (Acumedia, HX006100008, Lansing, MI, USA) suplementado com emulsão de gema de ovo com telurito de potássio (Egg Yolk com Telurito, NEWPROV, Pinhais, Paraná, Brasil) e incubação a $37^{\circ} \mathrm{C}$ por $48 \mathrm{~h}$. A confirmação das colônias típicas e atípicas foi realizada pelos testes de coagulase (Coagu-plasma LB, Laborclin, Pinhais, Paraná, Brasil) e catalase (Laborclin, Pinhais, Paraná, Brasil). Os resultados das contagens foram expressos em unidades formadoras de colônia (UFC)/g de amostra.
A pesquisa de Salmonella sp. foi realizada utilizando os caldos de enriquecimento Selenito-Cistina (Selenite Cystine Broth - DIFCO ${ }^{\mathrm{TM}}$, 268740, Le Pont de Claix, France) e Tetrationato-Novobiocina de Mueller Kauffmann (Muller-Kauffmann Tetrathionat Novobiocin - Merck 1.05878.0500, Darmstadt, Germany) e os ágares seletivos SS (Salmonella-Shighella-HIMEDIA, M108, Mumbai, Índia) e XLD (Agar Xilose Lisina Desoxicolato, HIMEDIA, M031, Mumbai, Índia). O kit bioquímico Rugai com Lisina (NEWPROV, Pinhais, Paraná, Brasil) foi utilizado para identificação presuntiva de Salmonella e a confirmação do gênero foi realizada por soro-aglutinação em lâminas utilizando-se anti-soros poli-somático e flagelar (Soro Salmonella polivalente, PROBAC, São Paulo, SP, Brasil) (BRASIL, 1995; 2003).

\section{Resistência antimicrobiana}

Para a avaliação da resistência antimicrobiana foram utilizadas 62 colônias de enterobactérias isoladas de amostras de pele e de peito das carcaças de frango orgânico e 51 colônias de amostras de frango convencional. As colônias foram isoladas a partir de uma alçada da primeira diluição das amostras $\left(10^{-1}\right)$, estriada em ágar MacConkey (HIMEDIA, M081, Mumbai, Índia) com incubação a $35^{\circ} \mathrm{C}$ por $24 \mathrm{~h}$ (SILVA et al., 2010). As colônias vermelhas características da família Enterobacteriaceae foram submetidas ao teste de resistência antimicrobiana pela técnica de disco-difusão (Método de Kirby-Bauer) em ágar Mueller Hinton (BIOTEC, Pinhais, Paraná, Brasil), utilizando suspensão bacteriana com densidade equivalente a 0,5 na escala nefelométrica de Mc Farland (Nefelobac, PROBAC, São Paulo, $\mathrm{SP}$, Brasil). Foram testados 14 antibióticos (NEWPROV, Pinhais, Paraná, Brasil) com as seguintes concentrações nos discos: ácido nalidíxico $(30 \mu \mathrm{g})$, amicacina $(30 \mu \mathrm{g})$, amoxicilina + ácido clavulânico $(20 \mu \mathrm{g})$, ampicilina $(10 \mu \mathrm{g})$, cefalotina (30 $\mu \mathrm{g})$, ciprofloxacina $(5 \mu \mathrm{g})$, cloranfenicol $(30 \mu \mathrm{g})$, doxiciclina $(30 \mu \mathrm{g})$, estreptomicina (10 $\mu \mathrm{g})$, gentamicina $(10 \mu \mathrm{g})$, norfloxacina $(10 \mu \mathrm{g})$, sulfonamida $(300 \mu \mathrm{g})$, tetraciclina $(30 \mu \mathrm{g}) \mathrm{e}$ tobramicina $(10 \mu \mathrm{g})$ (MIRANDA et al., 2008; CLSI, 
2011). A avaliação da resistência dos isolados aos antimicrobianos foi determinada pela medida dos halos formados em milímetros seguindo os padrões interpretativos para Enterobacteriaceae do Clinical and Laboratory Standards Institute (CLSI, 2011). Em todas as análises foi utilizada como controle positivo a cepa de Escherichia coli ATCC 25922 (NEWPROV, Pinhais, Paraná, Brasil).

\section{Análise estatística}

Os resultados das contagens microbianas foram comparados entre marcas dentro de cada grupo (orgânico e convencional) e entre os grupos. Para a análise estatística, os valores das contagens microbianas foram convertidos em $\log 10 \mathrm{UFC} / \mathrm{g}$. A comparação das contagens em cada marca dentro dos grupos foi realizada por análise de variância (ANOVA) e teste de Tukey para a comparação das médias $(\mathrm{P}<0,05)$. A comparação das contagens entre os grupos orgânico e convencional foi realizada pelo teste de Kolmogorov-Smirnov, devido à heterogeneidade das variâncias entre as contagens dos grupos orgânico e convencional.
A resistência antimicrobiana foi analisada descritivamente pelo cálculo da frequência absoluta e relativa (\% de resistência). A verificação de diferenças entre a frequência de resistência do grupo orgânico e do grupo convencional foi realizada pelo teste do Qui-quadrado $\left(\chi^{2}\right)(\mathrm{P}<0,05)$. Todos os cálculos foram realizados com o software estatístico Statgraphics Plus versão 4.1 para Windows, Statistical Graphics Corporation, Warrenton, VA, United States.

\section{Resultados e Discussão}

Entre os grupos orgânico e convencional houve diferença para as contagens de psicrotróficos, E. coli e Staphylococcus coagulase positiva com maiores valores para o grupo orgânico $(\mathrm{P}<0,05)$. Para a contagem de mesófilos e coliformes totais não foi observada diferença significativa $(\mathrm{P}>0,05)$ entre os grupos orgânico e convencional. Todas as amostras analisadas de ambos os sistemas de criação apresentaram ausência de Salmonella sp. em 25 g (Tabela 1).

TABELA 1: Valores médios para a contagem de mesófilos, psicrotróficos, coliformes totais (CT), Escherichia coli (EC), Staphylococcus coagulase positiva (S. coag.+) e pesquisa de Salmonella sp. nas carcaças de frango orgânico e convencional ( $\mathrm{n}=5$ amostras por marca; $\mathrm{n}$ total $=50$ amostras)

\begin{tabular}{|c|c|c|c|c|c|c|}
\hline $\begin{array}{c}\text { Marcas } \\
\text { avaliadas }\end{array}$ & $\begin{array}{l}\text { Mesófilos } \\
\text { (UFC/g) }\end{array}$ & $\begin{array}{l}\text { Psicrotróficos } \\
\text { (UFC/g) }\end{array}$ & $\begin{array}{c}\mathrm{CT} \\
(\mathrm{UFC} / \mathrm{g})\end{array}$ & $\mathrm{EC}(\mathrm{UFC} / \mathrm{g})$ & $\begin{array}{l}\text { S. coag. + } \\
\text { (UFC/g) }\end{array}$ & $\begin{array}{l}\text { Salmonella sp. } \\
\qquad(25 \mathrm{~g})\end{array}$ \\
\hline $\mathrm{OA}$ & $4 \times 10^{4 \mathrm{c}}$ & $3,5 \times 10^{4 b}$ & $5 \times 10^{3 \mathrm{~b}}$ & $3,1 \times 10^{3 b}$ & $1 \times 10^{1 \mathrm{~b}}$ & ausência \\
\hline $\mathrm{OB}$ & $2,5 \times 10^{7 a}$ & $9,2 \times 10^{4 a}$ & $1,9 \times 10^{7 a}$ & $9,6 \times 10^{6 a}$ & $6 \times 10^{2 \mathrm{ab}}$ & ausência \\
\hline $\mathrm{OC}$ & $8,6 \times 10^{4 \mathrm{bc}}$ & $2,9 \times 10^{4 b}$ & $4,8 \times 10^{3 b}$ & $3,1 \times 10^{3 b}$ & $1 \times 10^{3 \mathrm{ab}}$ & ausência \\
\hline OD & $1,3 \times 10^{4 \mathrm{~d}}$ & $7,7 \times 10^{3 \mathrm{c}}$ & $2,2 \times 10^{3 \mathrm{c}}$ & $6,2 \times 10^{2 c}$ & $8,1 \times 10^{2 a b}$ & ausência \\
\hline $\mathrm{OE}$ & $1,2 \times 10^{5 b}$ & $4,4 \times 10^{4 b}$ & $7,6 \times 10^{2 \mathrm{c}}$ & $3,2 \times 10^{2 \mathrm{c}}$ & $3,9 \times 10^{3 a}$ & ausência \\
\hline Média & $5,1 \times 10^{6 \mathrm{~A}}$ & $4,1 \times 10^{4 \mathrm{~A}}$ & $3,8 \times 10^{6 \mathrm{~A}}$ & $1,9 \times 10^{6 \mathrm{~A}}$ & $1,3 \times 10^{3 \mathrm{~A}}$ & ausência \\
\hline $\mathrm{CA}$ & $2 \times 10^{5 a}$ & $1,7 \times 10^{4 b}$ & $4,9 \times 10^{4 a}$ & $3,1 \times 10^{4 a}$ & $1 \times 10^{1 \mathrm{aa}}$ & ausência \\
\hline $\mathrm{CB}$ & $1,3 \times 10^{5 \mathrm{a}}$ & $5,2 \times 10^{4 \mathrm{a}}$ & $1,5 \times 10^{4 a b}$ & $2,4 \times 10^{3 a b}$ & $4 \times 10^{2 a}$ & ausência \\
\hline $\mathrm{CC}$ & $1,2 \times 10^{5 a}$ & $5,2 \times 10^{4 a}$ & $4,3 \times 10^{3 \mathrm{ab}}$ & $2,2 \times 10^{3 \mathrm{ab}}$ & $1,2 \times 10^{3 \mathrm{a}}$ & ausência \\
\hline $\mathrm{CD}$ & $3,2 \times 10^{4 b}$ & $1,7 \times 10^{3 \mathrm{c}}$ & $1,1 \times 10^{3 b}$ & $4,2 \times 10^{2 \mathrm{c}}$ & $2,1 \times 10^{2 a}$ & ausência \\
\hline $\mathrm{CE}$ & $1 \times 10^{4 \mathrm{c}}$ & $2,8 \times 10^{3 \mathrm{c}}$ & $1,7 \times 10^{3 b}$ & $6,2 \times 10^{2 b c}$ & $2,1 \times 10^{2 \mathrm{a}}$ & ausência \\
\hline Média & $9,8 \times 10^{4 \mathrm{~A}}$ & $2,5 \times 10^{4 \mathrm{~B}}$ & $1,4 \times 10^{4 \mathrm{~A}}$ & $7,4 \times 10^{3 \mathrm{~B}}$ & $4,1 \times 10^{2 \mathrm{~B}}$ & ausência \\
\hline
\end{tabular}

$\mathrm{OA}$ a $\mathrm{OE}=$ marcas de frango orgânico $\mathrm{CA}$ a $\mathrm{CE}=$ marcas de frango convencional. Valores médios com letras minúsculas diferentes na mesma coluna indicam diferença significativa entre as marcas dentro de cada grupo (orgânico e convencional) $(\mathrm{P}<0,05)$. Valores com letras maiúsculas diferentes na mesma coluna indicam diferença significativa $(\mathrm{P}<0,05)$ entre os grupos orgânico e convencional. 
Houve diferença nas contagens microbianas entre as marcas dentro do grupo orgânico e dentro do grupo convencional $(\mathrm{P}<0,05)$, contudo as contagens microbianas no grupo orgânico apresentaram maior amplitude de valores. No grupo orgânico a marca OB apresentou as maiores contagens de mesófilos, psicrotróficos, coliformes totais e $E$. coli em relação às demais marcas. No grupo convencional, a marca $\mathrm{CE}$ mostrou contagens inferiores às demais marcas para a maioria dos micro-organismos avaliados $(\mathrm{P}<0,05)$.

Os micro-organismos aeróbios mesófilos representam a carga microbiana dos alimentos e são indicativos de limpeza, desinfecção e controle de temperatura durante o processamento industrial, transporte e armazenamento dos alimentos (JAY, 2005). Apesar de não haver limite para contagem de aeróbios mesófilos na legislação federal brasileira para a carne de frango, o Código Sanitário do Estado de São Paulo, estabelece que a contagem máxima de aeróbios mesófilos em carnes cruas deve ser 3,0 x $10^{6}$ UFC/g (SÃO PAULO, 1992). Considerando esse limite, todas as marcas do grupo convencional e a maioria das marcas do grupo orgânico, com exceção da marca $\mathrm{OB}$, apresentaram-se em acordo com a legislação.

As contagens de mésofilos verificadas nas carcaças de frango avaliadas mostraram-se superiores às encontradas por Miyagusku et al. (2003), Moreira et al. (2008) e Oliveira et al. (2009) em carcaças de frango convencional.

Para psicrotróficos, as contagens em ambos os grupos apresentaram-se abaixo de $1,0 \times 10^{7} \mathrm{UFC} / \mathrm{g}$, número considerado limite para o aparecimento de deterioração microbiana em carnes (XAVIER, 1997; JAY, 2005). Quando a contagem de psicrotróficos em carne de frango atinge $1,0 \times 10^{8} \mathrm{UFC} / \mathrm{g}$ tem início a decomposição do tecido muscular e a limosidade na superfície da carne torna-se evidente, confirmando sua inaptidão ao consumo. Por isso, esses micro-organismos são indicadores de aptidão para consumo em carnes refrigeradas ou congeladas (JAY, 2005; AGUIAR, 2006). Charles et al. (2006) verificaram contagem de psicrotróficos em frango convencional próximas às obtidas no presente trabalho.
A contaminação por E. coli nas amostras de frango orgânico foi superior a duas vezes a contaminação encontrada nas amostras de frango convencional $(\mathrm{P}<0,05)$. As amostras de frango que apresentaram as maiores contagens de E. coli foram as das marcas $\mathrm{OB}$ (orgânica) e CA (convencional), com valores de 9,6 x $10^{6}$ e $3,1 \times 10^{4} \mathrm{UFC} / \mathrm{g}$, respectivamente. Tendo em vista, que a espécie $E$. coli é indicadora de contaminação fecal, sendo uma das que compõe o grupo coliforme termotolerante, e levando-se em conta que o limite máximo estabelecido pela legislação brasileira para esse grupo de microorganismos é de $1,0 \times 10^{4} \mathrm{UFC} / \mathrm{g}$ em carne in natura de frango (BRASIL, 2001), a contaminação das amostras das marcas $\mathrm{OB}$ e CA demonstra controle ineficiente da contaminação por $E$. coli em níveis aceitáveis durante o processamento dos frangos (SILVA et al., 2010).

Apesar das contagens médias de Staphylococcus coagulase positiva nas amostras de frango orgânico e frango convencional terem sido menores que a considerada crítica para a ocorrência de intoxicação alimentar, acima de $10^{5} \mathrm{UFC} / \mathrm{g}$ (LE LOIR et al., 2003), elas foram maiores que as relatadas por Aguiar (2006) em carne de frango produzido em sistema natural e convencional, ambos com valor $<10^{2} \mathrm{UFC} / \mathrm{g}$. Por sua vez, Moreira et al. (2008) observaram contagem de Staphylococcus acima de $10^{2}$ UFC/g em carne de frango resfriado e Freitas et al. (2001) contagem entre $4,0 \times 10^{1}$ e $2,6 \times 10^{4} \mathrm{UFC} / \mathrm{g}$ em carcaça de frango resfriado em Recife-PE.

A legislação brasileira (BRASIL, 2001) não exige a pesquisa de Salmonella em carnes resfriadas ou congeladas in natura de frango. No entanto, a ausência de Salmonella na carne de frango destinada ao consumo humano é uma importante condição para a inocuidade deste tipo de produto. Resultados semelhantes para ausência de Salmonella em carcaças de frango também foram obtidos por Lima (2005), Aguiar (2006), Teixeira e Lima (2008) e Pires et al. (2009). Por outro lado, Baú et al. (2001) e Oliveira et al. (2009) verificaram a presença de Salmonella em carcaça de frango convencional no comércio brasileiro. Nos EUA, Cui et al. (2005), isolaram salmonela em $61 \%$ das 198 carcaças de frango orgânico e em $44 \%$ das 61 carcaças de frango convencional comercializadas no estado de Maryland. Em outro estudo realizado no mesmo país, Bailey e 
Cosby (2005) observaram a presença de Salmonella em 15 das 25 (60\%) carcaças de frango orgânico avaliadas.

A despeito dos inúmeros fatores pós-criação que influenciam diretamente a microbiologia das carcaças de frango, particularmente as condições de abate e processamento industrial, os resultados obtidos no presente trabalho retratam os níveis de contaminação microbiológica do produto final, que se refletem na qualidade microbiológica do alimento disponível para o consumidor. Neste sentido, as carcaças de frango orgânico apresentaram contaminação por micro-organismos indicadores e patogênicos superior à contaminação das carcaças provenientes de sistema convencional. Apesar das criações orgânicas de frango serem, em geral, de menor porte, e apresentarem caráter artesanal e serem menos tecnificadas em relação às criações convencionais, todas as marcas orgânicas avaliadas possuíam registro nos Serviços de Inspeção Estadual ou Federal.

Resultados semelhantes de maior contaminação em carcaças de frango orgânico foram relatados por Miranda et al. (2008), que verificaram maior crescimento de enterobactérias em carcaças de frango orgânico comercializadas na Espanha em relação às convencionais.
As enterobactérias são causa importante de infecções do trato urinário, da corrente sanguínea, infecções abdominais e pneumonias e por isso, a resistência antimicrobiana nesses micro-organismos é preocupante e têm se mostrado cada vez mais frequente (PATERSON, 2006).

A avaliação da frequência de resistência antimicrobiana em bactérias isoladas da microbiota de animais de produção orgânica pode fornecer indícios da utilização de drogas antibióticas na produção e/ou terapêutica desses animais (MIRANDA et al., 2008).

A frequência de resistência antimicrobiana das enterobactérias isoladas das carcaças de frango convencional foi maior $(\mathrm{P}<0,05)$ que a dos isolados dos frangos orgânicos. A tetraciclina foi o antimicrobiano com a maior frequência de resistência tanto para as enterobactérias de frango orgânico quanto para as de frango convencional. Nos isolados de frango orgânico, a frequência de resistência para os outros treze antibióticos testados foi inferior a $30 \%$, ao passo que nos isolados de frango convencional, a frequência de resistência inferior a 30\% foi detectada para apenas seis antibióticos, amicacina, amoxicilina + ácido clavulânico, ácido nalidíxico, norfloxacina e ciprofloxacina (Figura 1).

FIGURA 1: Frequência de resistência antimicrobiana (\%) de enterobactérias isoladas das carcaças de frango convencional e orgânico.

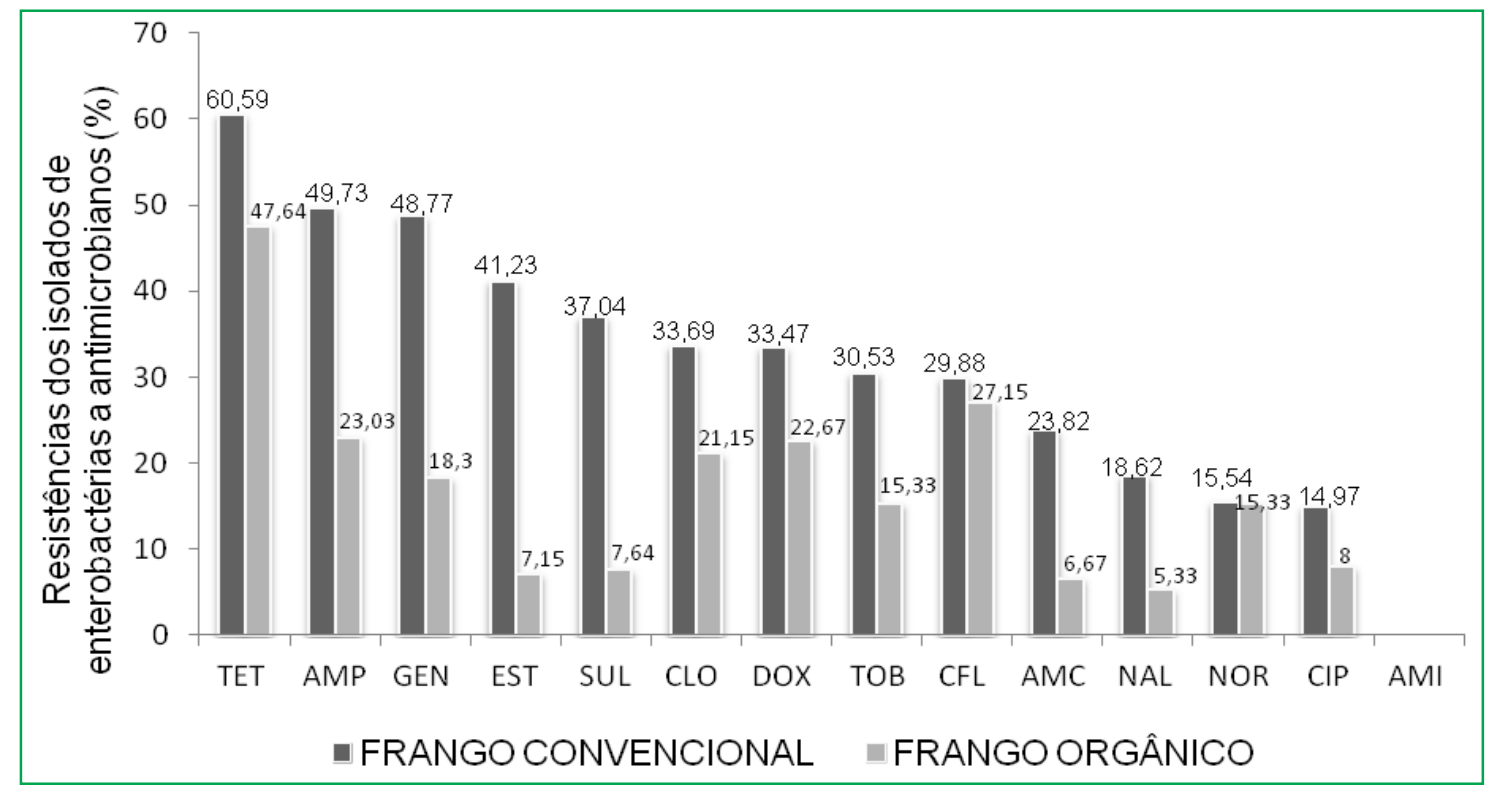

AMC: amoxiciclina + ác. clavulânico $(20 \mu \mathrm{g})$, AMI: amicacina $(30 \mu \mathrm{g}), \mathrm{AMP}$ : ampicilina $(10 \mu \mathrm{g})$, CFL: cefalotina (30 $\mu \mathrm{g})$, CIP: ciprofloxacina $(5 \mu \mathrm{g})$, CLO: cloranfenicol $(30 \mu \mathrm{g})$, DOX: doxiciclina $(30 \mu \mathrm{g})$, EST: estreptomicina $(10 \mu \mathrm{g})$, GEN: gentamicina (10 $\mu \mathrm{g})$, NAL: ácido nalidíxico $(30 \mu \mathrm{g})$, NOR: norfloxacina $(10 \mu \mathrm{g})$, SUL: sulfonamida $(300 \mu \mathrm{g})$, TET: tetraciclina $(30 \mu \mathrm{g})$ e TOB: tobramicina $(10 \mu \mathrm{g})$. 
Todas as enterobactérias isoladas tanto das carcaças orgânicas quanto convencionais foram sensíveis à amicacina.

Das enterobactérias isoladas das carcaças orgânicas, $22,58 \%$ (14) mostraram resistência múltipla, a quatro ou mais antimicrobianos, enquanto que dos isolados das carcaças convencionais, 56,86\% (29) apresentaram resistência antimicrobiana múltipla.

Os antibióticos que apresentaram as maiores diferenças nas frequências de resistência entre os isolados de frango orgânico e os isolados de frango convencional foram a estreptomicina e a sulfonamida, com resistência 5,7 vezes e 4,8 vezes superior nos isolados das carcaças convencionais. Por outro lado, as menores diferenças nas frequências de resistência dos isolados de frango orgânico em relação aos isolados de frango convencional foram para cefalotina e para norfloxacina.

Maiores frequências de resistência antimicrobiana em isolados de carcaças de frango convencional em comparação aos isolados de orgânicos também foram encontradas por Cui et al. (2005) nos EUA, que pesquisaram o perfil de resistência antimicrobiana de isolados de Salmonella provenientes de frangos orgânicos e convencionais e, verificaram que os isolados dos frangos orgânicos foram sensíveis a todos os 17 antimicrobianos testados e, os isolados de frangos convencionais foram resistentes a sete diferentes antimicrobianos. Miranda et al. (2008), na Espanha, encontraram 41,7\% de resistência nos isolados de frangos orgânicos e 63,3\% nos isolados de frangos convencionais. As frequências de resistência relatadas por esses últimos autores foram superiores às encontradas no presente trabalho para ambos os grupos de frango (22,58\% para o grupo orgânico e 56,86\% para o grupo convencional).

As tetraciclinas são drogas de amplo espectro de ação contra bactérias Gram positivas e Gram negativas, riquétsias, clamídias, alguns micoplasmas e protozoários, porém sua ação contra enterobactérias é cada vez mais limitada devido à resistência antimicrobiana (HIRSH; ZEE, 2003). O uso de drogas do grupo das tetraciclinas é proibido na produção de frangos de corte no Brasil (BRASIL, 2009), contudo as maiores frequências de resistência encontradas nas enterobactérias isoladas tanto dos frangos orgânicos quanto dos convencionais foi para a tetraciclina, com $47,64 \%$ e $60,59 \%$, respectivamente.

Além das tetraciclinas, estão proibidas como aditivos de rações para frangos de corte no Brasil as penicilinas, as sulfonamidas sistêmicas, a furazolidona, a nitrofurazona, a avoparcina e o cloranfenicol, (BRASIL, 2009).

Ribeiro et al. (2008) avaliaram a sensibilidade de cepas de Salmonella enteritidis isoladas de carcaças congeladas de frango convencional no Estado do Rio Grande do Sul à tetraciclina, ampicilina, ciprofloxacina, cloranfenicol, enrofloxacina, gentamicina, canamicina, ácido nalidíxico, nitrofurantoína, norfloxacina, polimixina B, estreptomicina e sulfazotrim. Esses autores constataram que todas as cepas de Salmonella apresentaram multirresistência, sendo de $100 \%$ para tetraciclina, estreptomicina e sulfazotrim. Também verificaram $86,36 \%$ de resistência ao ácido nalidíxico e $4,54 \%$ ao cloranfenicol.

O cloranfenicol teve importância como antimicrobiano por ter sido uma das primeiras drogas de largo espectro empregadas rotineiramente na medicina veterinária, agindo em bactérias Gram negativas e riquétsias. Porém, seu uso é responsável por efeitos colaterais no sistema hematopoiético, especialmente pela toxicidade à medula óssea. Esta toxicidade ocorre geralmente devido ao uso prolongado da droga e não necessariamente pela dosagem empregada no tratamento (PAIVA NETTO, 1989). Apesar de seu uso para tratamento veterinário ou alimentação animal ser proibido no Brasil desde 1998 (BRASIL, 1998; 1999), a resistência ao cloranfenicol foi verificada em $21,15 \%$ das enterobactérias isoladas de frangos orgânicos e 33,69\% das isoladas de frangos convencionais neste estudo.

Santos et al. (2000) verificaram ausência de resistência ao cloranfenicol nas 48 cepas de Salmonella isoladas de 150 carcaças de frango convencional congelado no estado de São Paulo. Contudo, observaram $100 \%$ de resistência à ampicilina, $75 \%$ à cefalotina, $52,1 \%$ à cefoxitina, $22,9 \%$ à tobramicina, $6,2 \%$ à 
polimixina $\mathrm{B}$ e tetraciclina, $4,2 \%$ à gentamicina e $2,1 \%$ à netilmicina, aztreonam e amicacina.

Miranda et al. (2008) verificaram taxas de resistência inferiores às obtidas neste trabalho para cloranfenicol $(11,1 \%)$, doxicilcina $(8,3 \%)$ e gentamicina $(8,3 \%)$ em enterobactérias isoladas de frangos orgânicos na Espanha.

Pessanha e Gontijo Filho (2001), ao isolarem enterobactérias da microbiota intestinal de frangos convencionais em diferentes fases de vida, verificaram que $57 \%$ das cepas foram resistentes à ampicilina e ao cloranfenicol, $67 \%$ à cefalotina, $74 \%$ ao ácido nalidíxico e $84 \%$ resistentes à tetraciclina.

A resistência aos antimicrobianos ocorre principalmente pelo uso generalizado e indiscriminado desses agentes, facilitando a transmissão de patógenos resistentes (VAN LOON et al., 2005). O uso abusivo de antibióticos como promotores de crescimento em rações para animais de produção têm contribuído para a resistência de bactérias da microbiota desses animais e representado perigo à saúde pelo consumo de alimentos de origem animal (VAN DEN BOGAARD; STOBBERINGH, 2000).

Apesar da proibição do uso de vários grupos de antibióticos como promotores de crescimento em frangos cortes no Brasil, um levantamento realizado em 2005 pela Secretaria de Estado da Saúde do Paraná (PARANÁ, 2005) em 28 cooperativas integradas e abatedouros de frango de corte do Estado demonstrou o uso das tetraciclinas $(6 \%)$ como promotores de crescimento e de tetraciclinas (11\%), penicilinas $(7 \%)$ e sulfonamidas (14\%) na terapêutica dessa espécie animal, mesmo sendo proibido. O levantamento também mostrou o uso indevido de drogas indicadas para terapêutica como promotores de crescimento, como a tiamulina (2\%), ciprofloxacina (6\%), olaquindox (1\%) (BRASIL, 2004), norfloxacina $(2,7 \%)$ e enrofloxacina $(33 \%)$ e ainda, o uso do carbadox (1\%) (BRASIL, 2005), que é contra indicado para frangos de corte, sendo recomendado apenas para suínos para uso medicinal ou como promotor de crescimento (PARANÁ, 2005).

Na produção orgânica, o emprego de antibióticos aprovados na avicultura convencional é autorizado somente para o tratamento de enfermidades e exclusivamente nos casos em que o uso dos tratamentos alternativos permitidos não esteja surtindo efeito e, por isso, haja sofrimento do animal. Neste caso, o período de carência deverá ser duas vezes superior ao período estipulado na bula do produto (BRASIL, 2008). Por isso, a resistência antimicrobiana encontrada nas enterobactérias isoladas dos frangos orgânicos pode ser resultante do uso de antibióticos nessas situações descritas ou da exposição dos animais a microorganismos antibiótico resistentes durante sua criação. Nesse sistema de criação, os frangos têm acesso a piquetes externos, onde o solo pode estar contaminado com fezes de pássaros e outras espécies silvestres que se deslocam entre granjas orgânicas e convencionais e, com isso, podem carrear microbiota antibiótico resistente. Outra possível explicação para a resistência antimicrobiana das bactérias isoladas de frango orgânico é a utilização permitida de pintinhos com até dois dias de vida provenientes de criações convencionais para a criação orgânica (BRASIL, 2008), os quais já poderiam ser portadores de microbiota antibiótico resistente.

Levando-se em consideração o maior valor de mercado da carne de frango orgânica em relação ao da carne convencional é importante que se garanta a conformidade do produto orgânico quanto à isenção do uso de antibióticos e, consequentemente, à ausência de resíduos destas drogas na carne. Desta forma, o monitoramento da frequência de resistência antimicrobiana na microbiota dos animais e de seus produtos pode auxiliar na detecção de práticas não permitidas no sistema orgânico e na redução do risco da transmissão de antibiótico-resistência à microbiota humana pelo consumo da carne de frango (MIRANDA et al., 2008).

A partir dos resultados, foi possível concluir que as carcaças de frango orgânico apresentaram maior contaminação microbiana $(\mathrm{P}<0,05)$ em comparação às carcaças convencionais. No entanto, a maioria das amostras de ambos os sistemas de criação apresentaram contagens microbianas dentro do limite legal permitido.

A tetraciclina foi o antibiótico com a maior frequência de resistência nos isolados das carcaças de ambos os sistemas de criação. 
A menor frequência de resistência antimicrobiana nos isolados das carcaças de frango orgânico indica o uso restrito ou ausente de antibióticos na produção desses animais e menor risco de transmissão de bactérias resistentes pelo consumo de carne de frango orgânico.

\section{Referências}

AGUIAR, A. P. S. Opinião do consumidor e qualidade da carne de frangos criados em diferentes sistemas de produção. 2006. 70 f. Dissertação (Mestrado em Ciências) - Universidade de São Paulo, Piracicaba. 2006.

BAILEY, J S.; COSBY, D. E. Salmonella prevalence in free-range and certified organic chickens. Journal of Food Protection, Des Moines, v. 68, n. 11, p. 2451-2453, 2005.

BAÚ, A. C.; CARVALHAU, J. B.; ALEIXO, J. A. G. Prevalência de Salmonella em produtos de frangos e ovos de galinha comercializados em Pelotas, RS, Brasil. Ciência Rural, Santa Maria, v. 31, n. 2, p. 303-307, 2001.

BRASIL - MINISTÉRIO DA AGRICULTURA, DO ABASTECIMENTO E DA REFORMA AGRÁRIA. Portaria no 8, de 23 de janeiro de 1995. Aprova as alterações introduzidas no método analítico de carcaças de aves e pesquisa de Salmonella. Diário Oficial da União, Brasília, DF, p. 1182, 27 jan. 1995.

BRASIL - MINISTÉRIO DA AGRICULTURA, PECUÁRIA E ABASTECIMENTO. Portaria no 210, de 10 de novembro de 1998. Regulamento técnico da inspeção tecnológica e higiênicosanitária de carne de aves. Diário Oficial da União, Brasília, DF, 26 nov. 1998.

BRASIL - MINISTÉRIO DA AGRICULTURA, PECUÁRIA E ABASTECIMENTO. Instrução Normativa no 42, de 20 de dezembro de 1999. Plano Nacional de controle de resíduos em produtos de origem animal. Diário Oficial da União, Brasília, DF, p. 213, 22 dez. 1999.

BRASIL. Resolução RDC ANVISA/MS no 12, de 02 de janeiro de 2001. Regulamento técnico sobre os padrões microbiológicos para alimentos. Diário Oficial da União, Brasília, DF, 10 jan. 2001.

BRASIL - MINISTÉRIO DA AGRICULTURA, PECUÁRIA E DO ABASTECIMENTO. SECRETARIA DE DEFESA AGROPECUÁRIA. Instrução Normativa no 62, de 26 de agosto de 2003. Oficializa os Métodos Analíticos Oficiais para Análises Microbiológicas para Controle de Produtos de Origem Animal e Água. Diário Oficial da União, Brasília, 18 de setembro de 2003.

BRASIL - MINISTÉRIO DA AGRICULTURA, PECUÁRIA E ABASTECIMENTO. Instrução Normativa no ${ }^{\mathbf{1 1}}$, de 24 de novembro de 2004. Instrução para a proibição da fabricação, importação, comercialização e uso da substância química denominada Olaquindoxitivo como aditivo promotor de crescimento em animais produtores de alimentos. Diário Oficial da União, Brasília, DF, de 27 nov. 2004.

BRASIL - MINISTÉRIO DA AGRICULTURA, PECUÁRIA E ABASTECIMENTO. Instrução Normativa no $\mathbf{3 5}$, de 124 de novembro de 2005. Instrução para a proibição da fabricação, importação, comercialização e uso de produtos destinados a alimentação animal contendo a substância química denominada
Carbadox. Diário Oficial da União, Brasília, DF, de 17 nov. 2005. BRASIL - MINISTÉRIO DA AGRICULTURA, PECUÁRIA E ABASTECIMENTO. Instrução Normativa no $\mathbf{6 4}^{\mathbf{6 4}}$, de 18 de dezembro de 2008. Aprova o regulamento técnico para os sistemas orgânicos de produção animal e vegetal. Diário Oficial da União, Brasília, DF, p. 21, 19 dez. 2008.

BRASIL - MINISTÉRIO DA AGRICULTURA, PECUÁRIA E ABASTECIMENTO. Instrução Normativa no 26, de 9 de julho de 2009. Regulamento Técnico para a fabricação, o controle de qualidade, a comercialização e o emprego de produtos antimicrobianos de uso veterinário. Diário Oficial da União, Brasília, DF, 10 jul. 2009.

CHARLES, N.; WILLIAMS, S. K.; RODRICK, G. E. Effects of packaging systems on the natural microflora and acceptability of chicken breast meat. Poultry Science, Champaign, v. 85, n. 10, p. 1798-1801, 2006.

CLSI - CLINICAL AND LABORATORY STANDARDS INSTITUTE/NCCLS. Performance Standards for Antimicrobial Susceptibility Testing, Wayne, 21ํㅡㄴ Informational Supplement, M100 S21, v. 31, n. 1, 2011.

CRABONE, G. T.; MOORI, R. G.; SATO, G. S. Fatores relevantes na decisão de compra de frango caipira e seu impacto na cadeia produtiva. Organizações Rurais \& Agroindustriais, Lavras, v. 7, n. 3, p. 312-323, 2005.

CUI, S.; GE, B.; ZHENG, J.; MENG, J. Prevalence and antimicrobial resistance of Campylobacter spp. and Salmonella serovars in organic chickens from Maryland retail stores. Applied and Environmental Microbiology, Washington, v. 71, n. 7, p. 4108-4111, 2005.

FANATICO, A. C.; CAVITT, L. C.; PILLAI, P. B.; EMMERT, J. L.; OWENS, C. M. Evaluation of slower-growing broiler genotypes grown with and without outdoor access: meat quality. Poultry Science, Champaign, v. 84, n. 11, p. 1785-1790, 2005.

FREITAS, M. F. L.; MOTA, R. A.; VILELA, S. M. O.; SENA, M. J.; BEZERRA, R. Cepas de Staphylococcus spp. isoladas de carcaças de frango comercializadas na cidade de Recife - PE, Brasil. Ciência Animal Brasileira, Goiânia, v. 2, n. 2, p. 139-145, 2001.

GRIGGS, J. P.; JACOB, J. P. Alternatives to antibiotics for organic poultry production. The Journal of Applied Poultry Research, Champaign, v. 14, n. 4, p. 750-756, 2005.

GUÉGUEN, L.; PASCAL, G. Le point sur la valeur nutritionnelle et sanitaire des aliments issus de l'agriculture biologique. Cahiers de Nutrition et de Diététique, Issy-Les-Moulineaux, v. 45, n. 3, p. 130-143, 2010.

HERMANSEN, J. E.; STRUDSHOLM, K.; HORSTED, K. Integration of organic animal production into land use with special reference to swine and poultry. Livestock Production Science, Philadelphia, v. 90, n. 1, p. 11-26, 2004.

HIRSH, D. C.; ZEE, Y. C. Microbiologia veterinária. Rio de Janeiro: Guanabara Koogan, 2003. 446 p.

JAY, J. M. Microbiologia de alimentos. 6 ed. Porto Alegre: Artmed, 2005. 712 p.

KILONZO-NTHENGE, A.; NAHASHON, S. N.; CHEN, F.; ADEFOPE, N. Prevalence and antimicrobial resistance of pathogenic bacteria in chicken and guinea fowl. Poultry Science, Champaign, v. 87, n. 9, p. 1841-1848, 2008. 
LE LOIR, Y.; BARON, F.; GAUTIER, M. Staphylococcus aureus and food poisoning. Genetic Molecular Research, Ribeirão Preto, v. 2 , n. 1 , p. $63-76,2003$.

LIMA, A. M. C. Avaliação de dois sistemas de produção de frango de corte: uma visão multidisciplinar. 2005. $111 \mathrm{f}$. Tese (Doutorado em Engenharia Agrícola) - Universidade Estadual de Campinas, Campinas. 2005.

MIRANDA, J. M.; VÁZQUEZ, B. I.; FENTE, C. A.; BARROSVELÁZQUEZ, J.; CEPEDA, A.; FRANCO, C. M. Antimicrobial resistance in Enterobacteriaceae strains isolated from organic chicken, conventional chicken and conventional turkey meat: a comparative survey. Food Control, Reading, v. 19, n. 4, p. $412-$ 416, 2008.

MIYAGUSKU, L.; CHEN, F.; LEITÃO, M. F. F.; BAFFA, O. Avaliação microbiológica e sensorial da vida-útil de cortes de peito de frangos irradiados. Ciência e Tecnologia de Alimentos, Campinas, v. 23, supl., p. 7-16, 2003.

MOREIRA, A. P. S.; GIOMBELLI, A.; LABANCA, R. A.; NELSON, D. L.; GLÓRIA, M. B. A. Effect of aging on bioactive amines, microbial flora, physico-chemical characteristics, and tenderness of broiler breast meat. Poultry Science, Champaign, v. 87, n. 9, p. 1868-1873, 2008.

OLIVEIRA, A. L.; PEREIRA, M. T.; BUENO, P. H. S.; OLIVEIRA, R. B. P.; PINTO, F. C.; CORREIA, R. F.; MACHADO, M. M. Qualidade microbiológica da carne de frango irradiada em embalagem convencional e a vácuo. Arquivo Brasileiro de Medicina Veterinária e Zootecnia, Belo Horizonte, v. 61, n. 5, p. 1210-1217, 2009

PAIVA NETTO, J. V. Antibióticos e quimioterápicos em medicina veterinária. São Paulo: Livraria Varela, 1989. 181 p.

PARANÁ. Levantamento do uso e comercialização de medicamentos veterinários em frango de corte no Estado do Paraná. Curitiba: SESA/ISEP, 2005. 25 p.

PATERSON, D. L. Resistance in gram-negative bacteria: Enterobacteriaceae. The American Journal of Medicine, Tucson, v. 119, n. 6, suppl. 1, p. 20-28, 2006.

PESSANHA, R. P.; GONTIJO FILHO, P. P. Uso de antimicrobianos como promotores de crescimento e resistência em isolados de Escherichia coli e de Enterobacteriaceae lactose-negativa da microflora fecal de frangos de corte. Arquivo Brasileiro de Medicina Veterinária e Zootecnia, Belo Horizonte, v. 53, n. 1, p. $111-115,2001$

PIRES, D. S. L.; PACHECO, M. S.; ROLIM, M. B. Q.; SANTANA, A. L.; MOURA, A. P. B. L. Pesquisa de Salmonella spp. e coliformes termotolerantes em carcaças de frangos in natura comercializados no Distrito Sanitário V da Cidade do Recife - PE. Medicina Veterinária, Recife, v. 3, n. 1, p. 31-36, 2009.
RIBEIRO, A. R.; KELLERMANN, A.; SANTOS, L. R.; NASCIMENTO, V. P. Resistência antimicrobiana em Salmonella enteritidis isoladas de amostras clínicas e ambientais de frangos de corte e matrizes pesadas. Arquivo Brasileiro de Medicina Veterinária e Zootecnia, Belo Horizonte, v. 60, n. 5, p. 1259-1262, 2008 .

REMBIAŁKOWSKA, E.; ŚREDNICKA, D. Organic food quality and impact on human health. Agronomy Research, Saku, v. 7, n. 2, p. 719-727, 2009.

SANTOS, D. M. S.; JUNIOR, A. B.; FERNANDES, S. A.; TAVECHIO, A. T.; AMARAL, L. A. Salmonella em carcaças de frango congeladas. Pesquisa Veterinária Brasileira, Seropédica, v. 20 , n. 1 , p. $39-42,2000$

SÃO PAUlO - SECRETARIA DE SAÚDE. Código Sanitário: Decreto $\mathrm{n}^{\mathrm{o}}$ 12.342, de 27 de setembro de 1978: regulamento da promoção, preservação e recuperação da saúde no campo da competência da Secretaria de Estado da Saúde (revisto e atualizado até dezembro de 1990), 5. ed. São Paulo: IMESP, 1992. 412 p.

SILVA, N.; JUNQUEIRA, V. C. A.; SILVEIRA, N. F. A.; TANIWAKI, M. H.; SANTOS, R. F. S.; GOMES, R. A. R. Manual de métodos de análise microbiológica de alimentos e água. 4. ed. São Paulo: Livraria Varela, 2010. 624 p.

TEIXEIRA, L. C.; LIMA, A. M. C. Ocorrência de Salmonella e Listeria em carcaças de frango oriundas de dois sistemas de criação no município de Campinas, SP. Archives of Veterinary Science, Curitiba, v. 13, n. 3, p. 191-196, 2008.

TUYTTENS, F.; HEYNDRICKX, M.; BOECK, M. D.; MOREELS, A.; VAN NUFFEL, A.; VAN POUCKE, E.; VAN COILLIE, E.; VAN DONGEN, S.; LENS, L. Broiler chicken health, welfare and fluctuating asymmetry in organic versus conventional production systems. Livestock Science, Philadelphia, v. 113, n. 2, p. 123-132, 2008 .

VAN DEN BOGAARD, A. E.; STOBBERINGH, E. E. Epidemiology of resistance to antibiotics. Links between animals and humans. International Journal of Antimicrobial Agents, London, v. 14, n. 4, p. 327-335, 2000

VAN LOON, H. J.; VRIENS, M. R.; FLUIT, A. C.; TROESLTRA, A.; VAN DER WERKEN, C.; VERHOEF, J.; BONTEN, M. J. M. Antibiotic rotation and development of gram-negative antibiotic resistance. American Journal of Respiratory and Critical Care Medicine, New York, v. 171, n. 5, p. 480-487, 2005.

XAVIER, C. V.A. Métodos químicos e físicos para prolongamento da vida de prateleira da carne de frango refrigerada. 1997. 141 f. Tese (Doutorado em Tecnologia de Alimentos) - Universidade Estadual de Campinas, Campinas. 1997. 